\title{
Workplace Exposure to Titanium Dioxide Nanopowder Released from a Bag Filter System
}

\author{
Jun Ho Ji, ${ }^{1,2}$ Jong Bum Kim, ${ }^{3,4}$ Gwangjae Lee, ${ }^{1}$ Jung-Hun Noh, ${ }^{5}$ \\ Se-Jin Yook, ${ }^{5}$ So-Hye Cho, ${ }^{6}$ and Gwi-Nam Bae ${ }^{3,4,7}$ \\ ${ }^{1}$ EcoPictures Co. Ltd., Seoul 137-865, Republic of Korea \\ ${ }^{2}$ Research \& Business Foundation, Sungkyunkwan University, Suwon 440-746, Republic of Korea \\ ${ }^{3}$ Center for Environment, Health, and Welfare Research, Korea Institute of Science and Technology, Seoul 136-791, Republic of Korea \\ ${ }^{4}$ Green School, Korea University, Seoul 136-713, Republic of Korea \\ ${ }^{5}$ School of Mechanical Engineering, Hanyang University, Seoul 133-791, Republic of Korea \\ ${ }^{6}$ Center for Materials Architecture, Korea Institute of Science and Technology, Seoul 136-791, Republic of Korea \\ ${ }^{7}$ University of Science and Technology, Daejeon 305-303, Republic of Korea
}

Correspondence should be addressed to Gwi-Nam Bae; gnbae@kist.re.kr

Received 17 December 2014; Revised 12 March 2015; Accepted 12 March 2015

Academic Editor: Vladimir Murashov

Copyright (c) 2015 Jun Ho Ji et al. This is an open access article distributed under the Creative Commons Attribution License, which permits unrestricted use, distribution, and reproduction in any medium, provided the original work is properly cited.

Many researchers who use laboratory-scale synthesis systems to manufacture nanomaterials could be easily exposed to airborne nanomaterials during the research and development stage. This study used various real-time aerosol detectors to investigate the presence of nanoaerosols in a laboratory used to manufacture titanium dioxide $\left(\mathrm{TiO}_{2}\right)$. The $\mathrm{TiO}_{2}$ nanopowders were produced via flame synthesis and collected by a bag filter system for subsequent harvesting. Highly concentrated nanopowders were released from the outlet of the bag filter system into the laboratory. The fractional particle collection efficiency of the bag filter system was only $20 \%$ at particle diameter of $100 \mathrm{~nm}$, which is much lower than the performance of a high-efficiency particulate air (HEPA) filter. Furthermore, the laboratory hood system was inadequate to fully exhaust the air discharged from the bag filter system. Unbalanced air flow rates between bag filter and laboratory hood systems could result in high exposure to nanopowder in laboratory settings. Finally, we simulated behavior of nanopowders released in the laboratory using computational fluid dynamics (CFD).

\section{Introduction}

It is estimated that millions of new workers and researchers will be exposed to engineered nanomaterials (ENMs) in occupational environments [1]. Various nanoaerosol sources in ENM manufacturing workplaces show complex relations to ENM exposure assessment. While identifying the sources, it becomes necessary to distinguish between ENMs and incidental nanoaerosols [2].

Many recent studies have investigated ENM exposure. Airborne multiwalled carbon nanotubes (MWCNTs) released within a research facility were measured via personal and area air sampling and by real-time aerosol monitoring [37]. Lee et al. [8] monitored potential exposure to nanoaerosols at workplaces where titanium dioxide $\left(\mathrm{TiO}_{2}\right)$ and silver $(\mathrm{Ag})$ nanoparticles were manufactured. A series of studies [912] attempted to differentiate task- or process-related ENMs from background or incidental nanoaerosols in workplaces.

However, a more urgent problem exists at the research and development stage in laboratories. Many researchers or students who manufacture ENMs using laboratory-scale synthesis systems could be easily exposed to airborne ENMs. Current knowledge indicates that a well-designed exhaust hood system with a high-efficiency particulate air (HEPA) filter can effectively remove ENMs. However, malfunction or failure of this system is not easily detected by regular activity, since ENMs may not be visible with the naked eye even when released at high concentrations. This occurs 
particularly when an automated ENM harvesting system is nonoperational or the design specification has low collection efficiency of ENMs.

The present study used various real-time aerosol detectors to investigate airborne nanopowders in a laboratory manufacturing $\mathrm{TiO}_{2}$. The $\mathrm{TiO}_{2}$ nanopowders were produced through a flame synthesis process and collected by a bag filter system for harvesting. We found high possibility of nanopowder exposure in the laboratory environment, due to low particle collection efficiency of the bag filter system. Unbalanced air flow rates were found between the nanopowder harvesting system and the laboratory canopy hood system. Finally, we simulated behavior of nanopowders released in the laboratory using computational fluid dynamics (CFD).

\section{Materials and Methods}

2.1. Nanopowder Laboratory. The $\mathrm{TiO}_{2}$ manufacturing laboratory consisted of $\mathrm{a} \mathrm{TiO}_{2}$ manufacturing room $(3.4 \times 9.4 \mathrm{~m})$ and a preparation room $(6.85 \times 9.4 \mathrm{~m})$. The diameter of the exhaust duct from the canopy hood was $200 \mathrm{~mm}$ and flow rate of exhaust air was $\sim 20 \mathrm{~m}^{3} / \mathrm{min}$. As shown in Figure 1, measurements were carried out at two monitoring positions on September 9-10, 2013. The main position A was near the flame synthesis system; simultaneous monitoring was conducted at subposition B, located near the entrance door of the laboratory, which was connected to a corridor. Comparing the data obtained at the main and subpositions showed whether nanopowders originated from the $\mathrm{TiO}_{2}$ manufacturing process. The building had a central air-conditioning system. However, the laboratory had no diffusers for supply air and had only local exhaust hoods connected to the roof fan for exhausting contaminated laboratory air. Therefore, the laboratory air was moved naturally or followed hood-induced air streams.

Flame synthesis was carried out in an open chamber. The precursor vapors, titanium (IV) isopropoxide (TTIP), and flammable gases such as $\mathrm{CH}_{4}$ were burnt together in a combustion reactor at $\sim 1,200^{\circ} \mathrm{C}$. The detailed $\mathrm{TiO}_{2}$ manufacturing procedure was reported by Park et al. [13]. The synthesized $\mathrm{TiO}_{2}$ nanopowders were automatically collected by a bag filter system, from which $\mathrm{TiO}_{2}$ nanopowders were subsequently harvested. The bag filter system had six cartridges made of polyester and an air-pulse was applied regularly to remove $\mathrm{TiO}_{2}$ nanopowders collected on the filters. The filtration area was $11.25 \mathrm{~m}^{2}$ and filtration velocity was $\sim 3.2 \mathrm{~cm} / \mathrm{s}$.

2.2. Experimental. Table 1 lists the real-time aerosol detectors used in this study. A scanning mobility particle sizer (SMPS, Nanoscan, model 3910, TSI, USA) was used to determine particle size distribution within the range $10-420 \mathrm{~nm}$. The device measures particle size distribution for a total scan time of $60 \mathrm{~s}$ ( $45 \mathrm{~s}$ scan time, $15 \mathrm{~s}$ retrace). An optical particle counter (OPC, portable aerosol spectrometer, model 1.109 , Grimm, Germany) was used to monitor particle size distribution within the range $0.25-32 \mu \mathrm{m}$ for every $60 \mathrm{~s}$. In addition, surface area concentrations of particles deposited in the alveolar regions of the lung were measured using a nanoparticle aerosol monitor (NAM, model AeroTrak 9000,
TSI, USA) with $\mathrm{PM}_{1}$ cyclone for every $60 \mathrm{~s}$. The air was sampled at flow rates of $0.75,1.2$, and $2.5 \mathrm{~L} / \mathrm{min}$ for SMPS, $\mathrm{OPC}$, and NAM, respectively.

We measured nanopowders at two monitoring positions (main and subpositions) to differentiate task- or processrelated nanopowder exposures from the background or incidental nanoaerosols. Three aerosol detectors were set at the main position and two (OPC and NAM) were set at the subposition. A portable aerosol sensor (Discmini, Matter Aerosol, Switzerland) was used to check the instant episode and spatial particle distribution at locations (1) to (10) in the laboratory. We moved the instrument between locations so that these measurements were not only spatially segregated but also temporally separated. For episodes of increasing concentration, the portable aerosol detector was very helpful in identifying the source locations. The morphology of airborne nanopowders was observed by scanning electron microscopy (SEM, model NOVA 600, FEI with an accelerating voltage of $30 \mathrm{kV}$ ). Membrane filter (Isopore membrane filter, pore size of $100 \mathrm{~nm}$ ) sets were used in air sampling for the SEM analysis, using a personal sampling pump (model GilAir Plus, Sensidyne, LP, USA) at $0.5 \mathrm{~L} / \mathrm{min}$.

\section{Results and Discussion}

3.1. Task-Based Exposure Characteristics in the $\mathrm{TiO}_{2}$ Laboratory. Figure 2 shows variations in particle concentrations measured using two real-time aerosol detectors, including the flame synthesis process of tasks 1 and 2. Surface area and mass concentrations of particles showed rapid increase at main position A during $\mathrm{TiO}_{2}$ synthesis. In contrast, particle concentrations at subposition $\mathrm{B}$ were unchanged. Since synthesized or agglomerated $\mathrm{TiO}_{2}$ powders were mostly $<100 \mathrm{~nm}$, as shown in Figure 3, surface area concentration monitored by NAM was more sensitive than $\mathrm{PM}_{10}$ mass concentration measured by OPC.

Figure 3 shows the particle size distributions measured using an SMPS. Before and after the synthesis process, the geometric mean particle diameter was approximately $100 \mathrm{~nm}$ and the total number concentration was approximately 10,000 particles $/ \mathrm{cm}^{3}$. However, during the synthesis process, the high number concentration at main position A prevented correct measurement of the particle size distribution. This suggests that the particle number concentration in the laboratory exceeded $10^{6}$ particles $/ \mathrm{cm}^{3}$, which is the upper limit of the Nanoscan device. For qualitative information, snap shots of particle size distribution during the synthesis are plotted in Figure 3. At 14:30-14:40, bimodal size distribution indicates that fresh synthesized $\mathrm{TiO}_{2}$ nanopowders of $\sim 20 \mathrm{~nm}$ and agglomerated $\mathrm{TiO}_{2}$ nanopowders of 50-200 nm were released. One hour later, the particle concentration decreased overall and a broad size band appeared.

Figure 4(a) shows the number concentration and geometric mean diameter of particles, measured using a Discmini, during the second synthesis task (task 2) at the ten locations shown in Figure 1. The geometric mean diameter was approximately $40 \mathrm{~nm}$ at the synthesis area, and these manufactured $\mathrm{TiO}_{2}$ nanopowders were released to the interior of the laboratory. This means that most of the airborne nanopowders in 


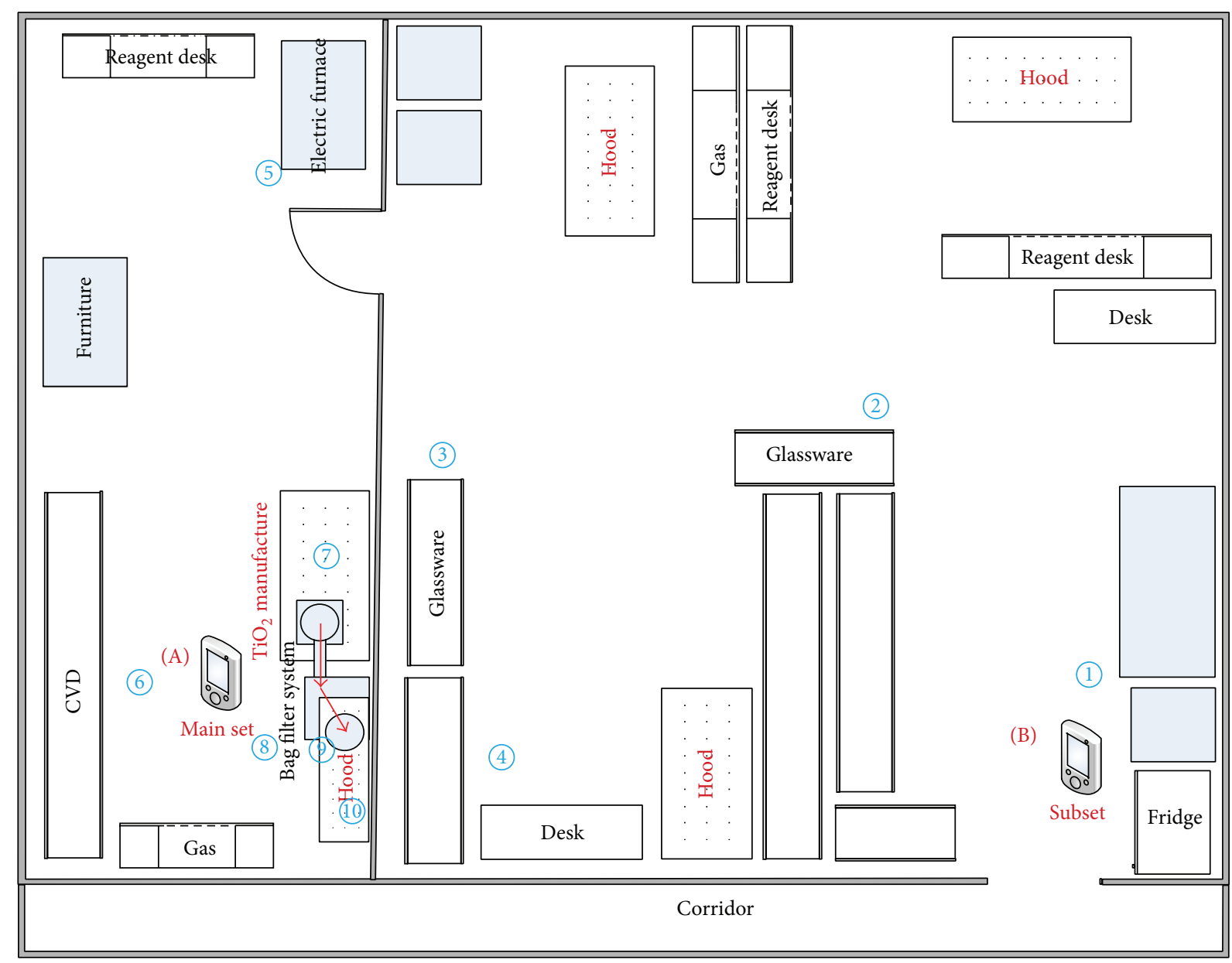

(a) Layout of the $\mathrm{TiO}_{2}$ manufacturing laboratory.

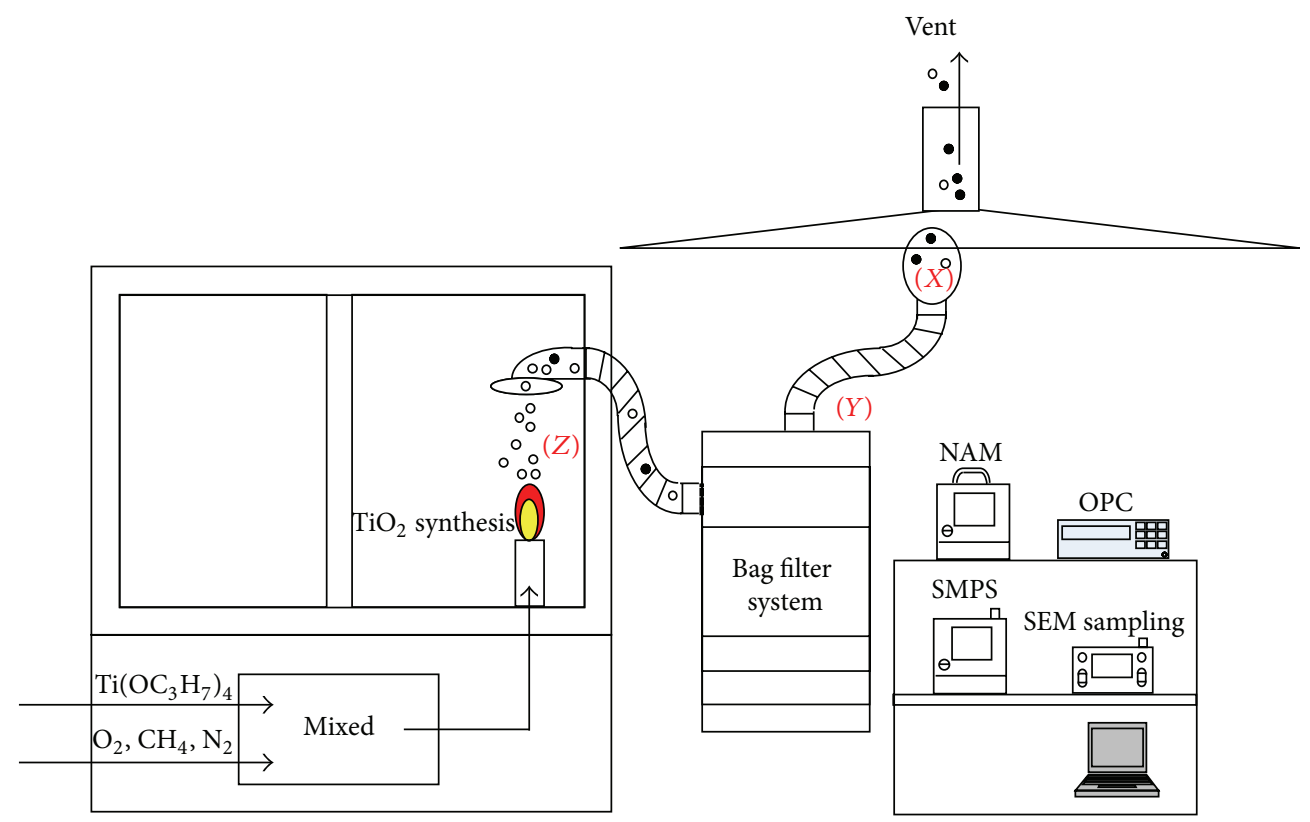

(b) Schematic of $\mathrm{TiO}_{2}$ synthesis, collection, and exhaust hood system.

FIGURE 1: Schematic of $\mathrm{TiO}_{2}$ manufacturing laboratory. 
TABLE 1: Aerosol detectors used in this study.

\begin{tabular}{|c|c|c|c|c|}
\hline & Specifications of instrument & Main set & Subset & $\begin{array}{l}\text { Portable aerosol } \\
\text { detector }\end{array}$ \\
\hline \multirow{4}{*}{$\begin{array}{l}\text { Particle size } \\
\text { distribution }\end{array}$} & $10-420 \mathrm{~nm}$ & \multirow{2}{*}{ SMPS (Nanoscan, TSI 3910) } & \multirow{4}{*}{$\begin{array}{l}\text { OPC (portable aerosol } \\
\text { spectrometer, Grimm 1.109) }\end{array}$} & \\
\hline & $<10^{6}$ particles $/ \mathrm{cm}^{3}$ & & & \\
\hline & $0.25-32 \mu \mathrm{m}$ & OPC (portable aerosol & & \\
\hline & $<2 \times 10^{6}$ particles $/ \mathrm{L}$ & spectrometer, Grimm 1.109) & & \\
\hline \multirow{3}{*}{$\begin{array}{l}\text { Particle number } \\
\text { concentration }\end{array}$} & $10-700 \mathrm{~nm}$ & & & \multirow{3}{*}{$\begin{array}{l}\text { Discmini } \\
\text { (Matter Aerosol) }\end{array}$} \\
\hline & $<10^{6}$ particles $/ \mathrm{cm}^{3} @ 20 \mathrm{~nm}$ & & & \\
\hline & $<5 \times 10^{5}$ particles $/ \mathrm{cm}^{3} @ 100 \mathrm{~nm}$ & & & \\
\hline \multirow{2}{*}{$\begin{array}{l}\text { Lung-deposited } \\
\text { surface area }\end{array}$} & $10-1,000 \mathrm{~nm}$ & \multirow{2}{*}{$\begin{array}{l}\text { NAM } \\
\text { (TSI AeroTrak 9000) }\end{array}$} & \multirow{2}{*}{$\begin{array}{l}\text { NAM } \\
\text { (TSI AeroTrak 9000) }\end{array}$} & \\
\hline & $<10^{4} \mu \mathrm{m}^{2} / \mathrm{cm}^{3}$ for A mode & & & \\
\hline SEM & & $\begin{array}{l}\text { Filter sampler } \\
\text { (pore size } 100 \mathrm{~nm})\end{array}$ & & \\
\hline
\end{tabular}

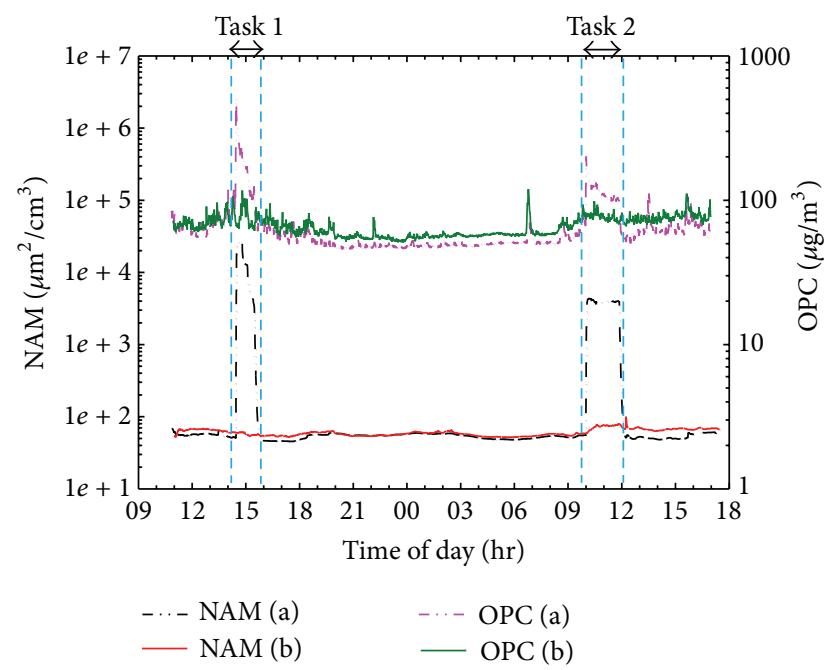

FIGURE 2: Concentration changes in particle mass from OPC and surface area from NAM during two $\mathrm{TiO}_{2}$ synthesis processes.

the synthesis room originated from leakage of the bag filter system during $\mathrm{TiO}_{2}$ synthesis. The mean particle diameter was similar to that of $\mathrm{TiO}_{2}$ produced by flame synthesis, which was mostly smaller than $50 \mathrm{~nm}$ [13]. On the other hand, indoor air in the preparation room showed relatively low particle concentration regardless of the distance from the source location. Here, the particle number concentration and the geometric mean diameter were approximately 10,000 particles $/ \mathrm{cm}^{3}$ and $60-70 \mathrm{~nm}$, respectively. These data are very similar to those of Figure 3 for the synthesis room prior to the synthesis task. A closed door separated the preparation room from the manufacturing room, with the result that particle number concentration was much higher in the manufacturing room, as shown in Figure 4(b).

Table 2 compares particle concentrations measured at positions $\mathrm{A}$ and $\mathrm{B}$ using three real-time aerosol detectors. During the task, the total number concentration of particles smaller than $700 \mathrm{~nm}$, measured by a Discmini, near the synthesis system was 200 times higher than that in

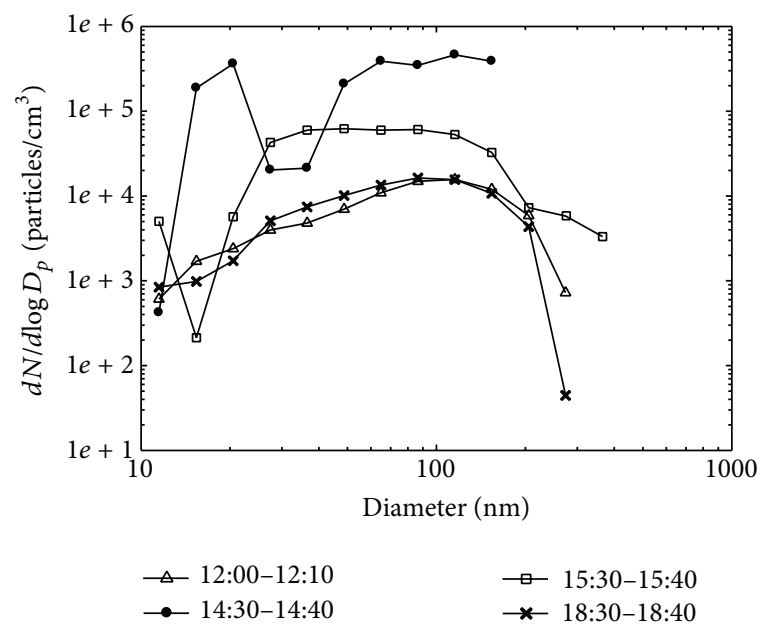

FIgure 3: Particle size distributions in the laboratory before, during, and after $\mathrm{TiO}_{2}$ synthesis.

the preparation room. However, the number concentration of particles larger than $250 \mathrm{~nm}$, measured by an OPC, near the synthesis system was only 1.98 times higher, implying that most nanopowders were smaller than $250 \mathrm{~nm}$.

3.2. Evaluation of Bag Filter Performance for Harvesting $\mathrm{TiO}_{2}$ Nanopowder. During the synthesis process, we could not evaluate the fractional particle collection efficiency of the bag filter system, due to the high number concentration and high temperature at the inlet of the collection equipment. As shown in Figure 1(b), we measured particle size distribution at both the inlet and outlet of the bag filter system. The performance was evaluated by comparison with indoor aerosol concentrations in conditions without synthesis process. The particle size distribution of indoor aerosols was similar to that shown in Figure 3. The fractional particle collection efficiency, $\eta_{f}$, was calculated by

$$
\eta_{f}=1-\frac{C_{\text {out }}}{C_{\text {in }}}
$$




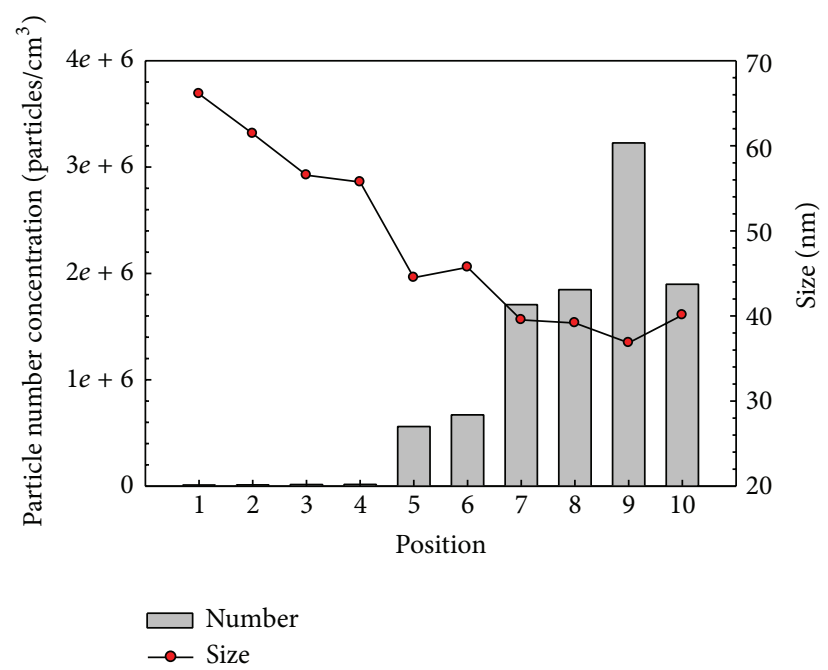

(a)

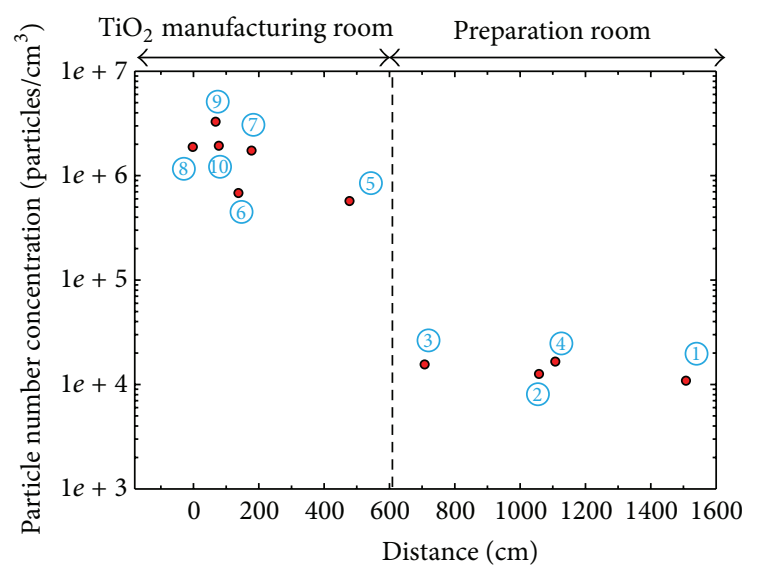

(b)

Figure 4: Particle size characteristics, measured by a Discmini, during the synthesis process: (a) particle number concentration and geometric mean diameter, and (b) particle number concentration with distance from the main position $\mathrm{A}$.

TABLE 2: Particle concentrations measured during $\mathrm{TiO}_{2}$ synthesis.

\begin{tabular}{|c|c|c|c|}
\hline & Main set $(A)$ & Subset $(B)$ & Ratio $(A / B)$ \\
\hline \multicolumn{4}{|l|}{ Background } \\
\hline OPC (particles $/ \mathrm{cm}^{3}$ ) & $717.3 \pm 14.0$ & $828.5 \pm 15.2$ & 0.87 \\
\hline $\mathrm{OPC}\left(\mu \mathrm{g} / \mathrm{m}^{3}\right)$ & $49.6 \pm 1.1$ & $57.6 \pm 1.1$ & 0.86 \\
\hline $\operatorname{NAM}\left(\mu \mathrm{m}^{2} / \mathrm{cm}^{3}\right)$ & $50.1 \pm 2.4$ & $53.4 \pm 2.0$ & 0.94 \\
\hline Discmini (particles $/ \mathrm{cm}^{3}$ ) & - & - & - \\
\hline \multicolumn{4}{|l|}{ Flame synthesis task } \\
\hline OPC (particles $\left./ \mathrm{cm}^{3}\right)$ & $1,332.6 \pm 188.1$ & $918.2 \pm 13.9$ & 1.50 \\
\hline OPC $\left(\mu \mathrm{g} / \mathrm{m}^{3}\right)$ & $116.4 \pm 18.4$ & $77.3 \pm 5.2$ & 1.45 \\
\hline $\operatorname{NAM}\left(\mu \mathrm{m}^{2} / \mathrm{cm}^{3}\right)$ & $3,930.2 \pm 243.2$ & $72.3 \pm 5.0$ & 54.3 \\
\hline Discmini (particles $/ \mathrm{cm}^{3}$ ) & $2 \times 10^{6}$ & $10^{4}$ & 200 \\
\hline
\end{tabular}

where $C_{\text {in }}$ is the number concentration at the system inlet and $C_{\text {out }}$ is that at the system outlet. We measured inlet aerosols at $Z$ for $C_{\text {in }}$. The aerosols at a position $20 \mathrm{~cm}$ inside flexible duct outlet of the system were measured, using a Nanoscan at $X$ for $C_{\text {out }}$.

Ten measurements were made sequentially at both the inlet and outlet using SMPS and OPC. Figure 5 shows the fractional particle collection efficiency of the $\mathrm{TiO}_{2}$ collection equipment. Particle collection efficiency at $100 \mathrm{~nm}$ was approximately $20 \%$, meaning that much of the $\mathrm{TiO}_{2}$ nanopowder generated by the flame synthesis was not collected in the bag filter equipment. For particles larger than $200 \mathrm{~nm}$, the fractional particle collection efficiency of the bag filter system appears to be negative. This finding might be a result of the reentrainment of aggregate particles composed of mainly $\mathrm{TiO}_{2}$ nanopowders. Due to the low collection efficiency of the bag filter system, $\mathrm{TiO}_{2}$ nanopowders exiting the system were partially deposited on the inner surface of the flexible duct. Subsequently, aggregate particles between 1 and
$10 \mu \mathrm{m}$ were detached from the duct surface and blown into the indoor air during operation of the bag filter system.

Figures 6(a) to 6(d) show the particle size distributions measured at main position (A) using the OPC during the two synthesis processes in order to analyze reentrainment of $\mathrm{TiO}_{2}$ aggregates. As shown in Figures 6(a) and 6(c), significant increase in the number concentration of particles smaller than $0.5 \mu \mathrm{m}$ was observed for the periods including tasks 1 and 2, respectively. Figures 6(b) and 6(d) show mass-based particle size distribution converted from the data of Figures 6(a) and 6(c), respectively. Here, the mass size distribution was obtained by means of Control Grimm-spectrometer software (v2.5.4). Significant increase in mass concentration of particles between 1 and $30 \mu \mathrm{m}$ is also seen, providing evidence of reentrainment from the inner surface of the outlet duct in the bag filter system. Due to the low performance of the bag filter system, penetrated $\mathrm{TiO}_{2}$ nanopowders were deposited on the inner surface of the outlet duct during the synthesis process. This phenomenon was confirmed by 


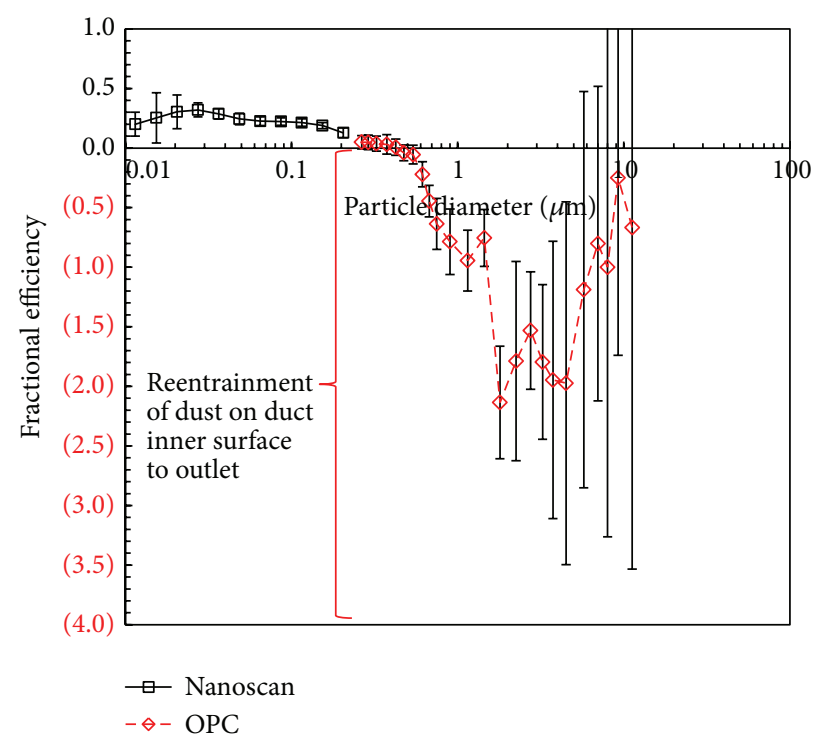

FIGURE 5: Fractional particle collection efficiency of the bag filter system.

visual inspection. These deposited aggregated $\mathrm{TiO}_{2}$ powders might subsequently be reentrained from the outlet duct of the collection system when the system is turned on.

\subsection{Effect of Unbalanced Air Flow Rates between Nanopowder} Harvesting System and Local Hood System. We measured the air flow rate of the bag filter system used for nanopowder harvesting and that of the local hood system described in Figure 1. Air velocity was measured using a multichannel anemomaster (model 1560, Kanomax, Japan) with an omnidirectional probe (model 0964-01/02). The air flow rates were estimated from the three-point velocity data measured at the cross sections of each duct inlet. The air flow rate of the bag filter system was approximately $30 \mathrm{~m}^{3} / \mathrm{min}$, compared with only $19.2 \mathrm{~m}^{3} / \mathrm{min}$ for the hood system. The $\mathrm{TiO}_{2}$ nanopowders that penetrated through the bag filter system were not fully removed by the local hood system; instead, large amounts of $\mathrm{TiO}_{2}$ nanopowders were transferred and diffused into the interior of the laboratory, as shown in Figure 2.

3.4. Numerical Simulation for Nanopowder Release in the Laboratory. In order to check whether or not aerosols could be effectively exhausted through the canopy hood, aerosol flow near the canopy hood was simulated using FLUENT commercial computational fluid dynamics (CFD) software. Figure 7 shows the calculation domain. Aerosol was released from a duct pipe with 90 -degree elbow, into the space beneath the canopy hood. The duct pipe and canopy hood were placed very close to a side wall of the laboratory room. The inner diameter of the duct pipe was $300 \mathrm{~mm}$, and that of the exhaust duct was $200 \mathrm{~mm}$. In reference to the real situation, the centerline of the upright part of the duct pipe was $200 \mathrm{~mm}$ off-center to that of the canopy hood. The flow rate of aerosol released from the duct pipe was $30 \mathrm{~m}^{3} / \mathrm{min}$, whereas that drawn into the canopy hood was $19.2 \mathrm{~m}^{3} / \mathrm{min}$. Ambient temperature and pressure were set at $293 \mathrm{~K}$ and $101.3 \mathrm{kPa}$, respectively. The flow was assumed to be three-dimensional, steady, incompressible, and turbulent. The standard k- $\varepsilon$ turbulence model was employed. The boundary conditions were the velocity inlet condition at the aerosol inlet of the duct pipe, the velocity outlet condition at the exhaust of the canopy hood, and the no-slip condition on the walls of the duct pipe, canopy hood, ceiling, and floor. The no-slip condition was also applied to the laboratory side wall near the canopy hood (dark-gray-colored wall in Figure 7), whereas the symmetry condition was imposed on the other side walls of the laboratory. The convergence criterion for iteratively solving the continuity, momentum, and energy equations was set at $10^{-6}$. The coupled set of governing equations was iteratively solved by using the finite volume method with SIMPLE algorithm. From the result of the grid dependence test, the number of grids was determined as approximately 7.8 million. After the flow field was obtained, particle trajectories were calculated using the discrete phase models (DPM), based on a Lagrangian reference frame. Particle sizes were selected as $20 \mathrm{~nm}, 100 \mathrm{~nm}$, and $5 \mu \mathrm{m}$. The forces considered to act on the particles were the gravitational force, Brownian force, and Stokes drag force with slip correction.

The fraction of particles exhausted through the canopy hood, the fraction entrained in the room air, and the fraction deposited in the duct pipe are almost same for the three particle sizes. As an example, the results for $5 \mu \mathrm{m}$ particle size are discussed. Figure 8 shows the predicted trajectories of 5 $\mu \mathrm{m}$ particles. After exiting the duct pipe, most of the aerosol particles were exhausted through the canopy hood. Some of the particles, however, were introduced to the laboratory room. Looking at the simulation results for the tested particle sizes, only $52 \%$ of aerosol particles injected from the duct pipe inlet were estimated to be exhausted through the canopy hood, and about $19 \%$ were predicted to be entrained in the air of the laboratory. This was mainly because the flow 


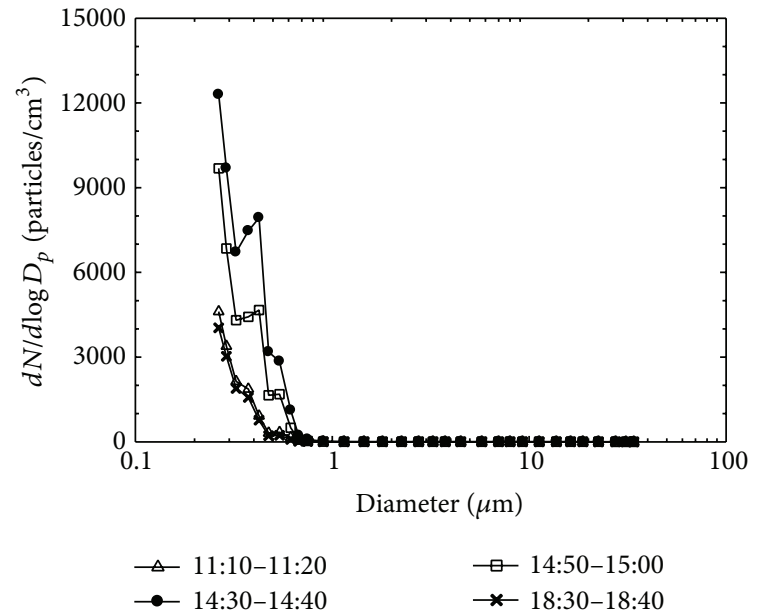

(a)

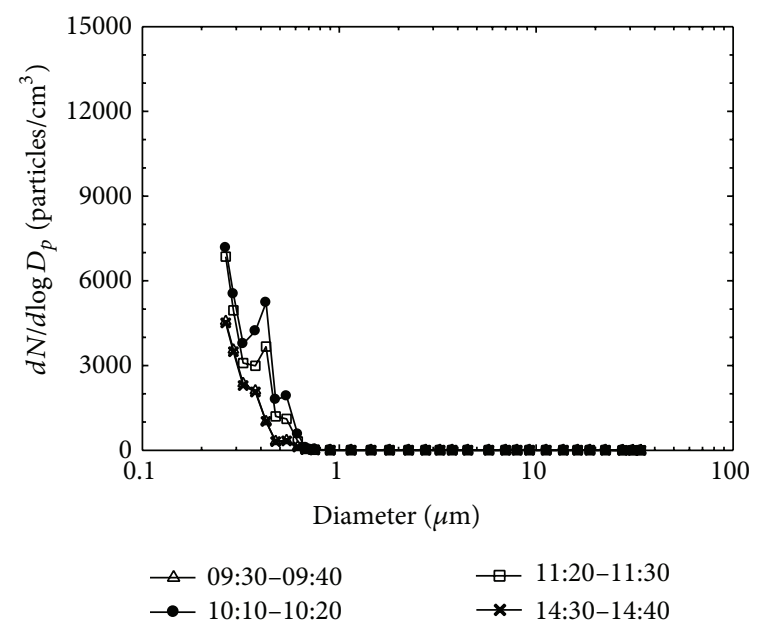

(c)

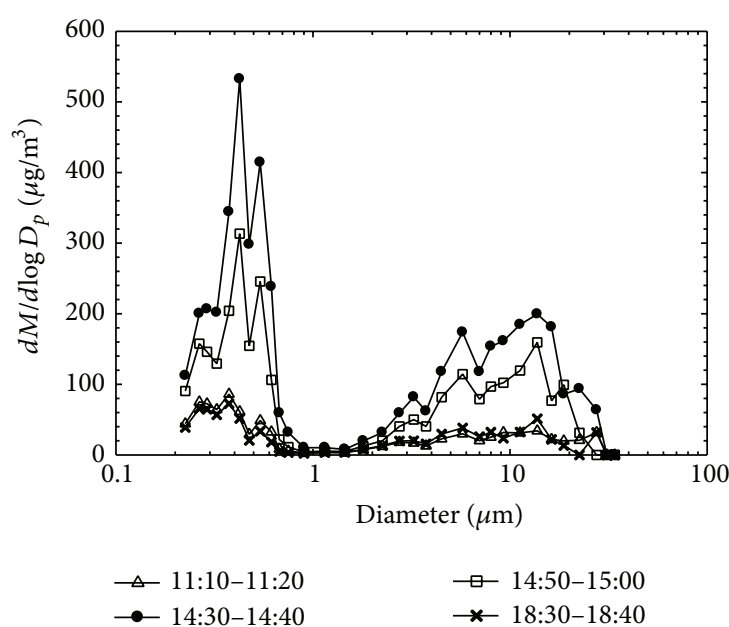

(b)
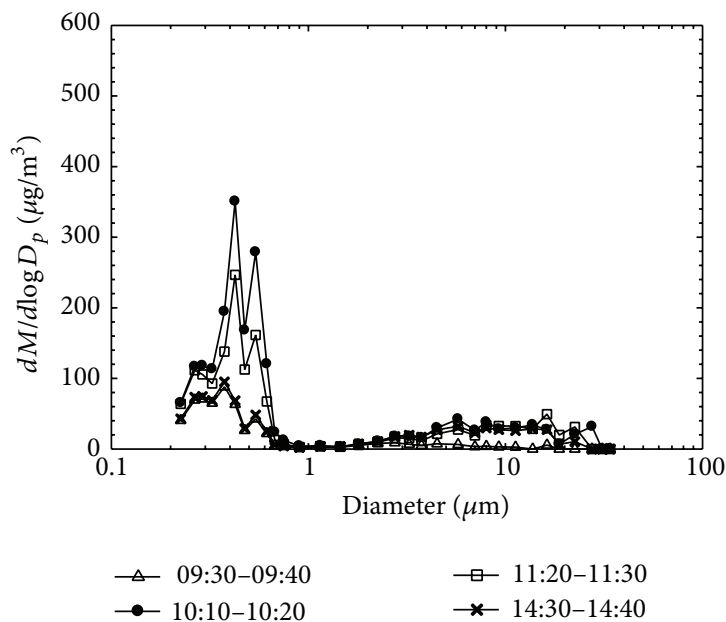

(d)

FIGURE 6: Analysis of particle size distribution measured using the OPC: comparison of number-based particle size distribution (a and c) and mass-based particle size distribution (b and d). Panels (a) and (b) refer to the period including task 1 , and (c) and (d) to the period including task 2.

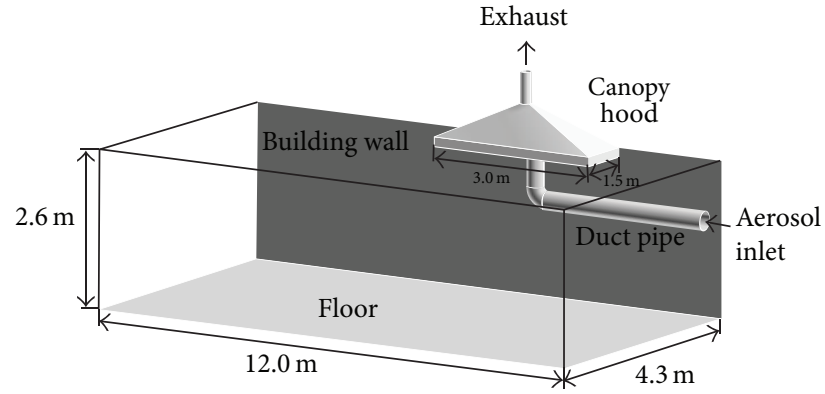

Figure 7: Schematic of calculation domain.

rate through the canopy hood $\left(19.2 \mathrm{~m}^{3} / \mathrm{min}\right)$ was less than that through the duct pipe $\left(30 \mathrm{~m}^{3} / \mathrm{min}\right)$. Therefore, it is of great importance to ensure sufficient suction flow rate of a canopy hood. Meanwhile, approximately $29 \%$ of aerosol

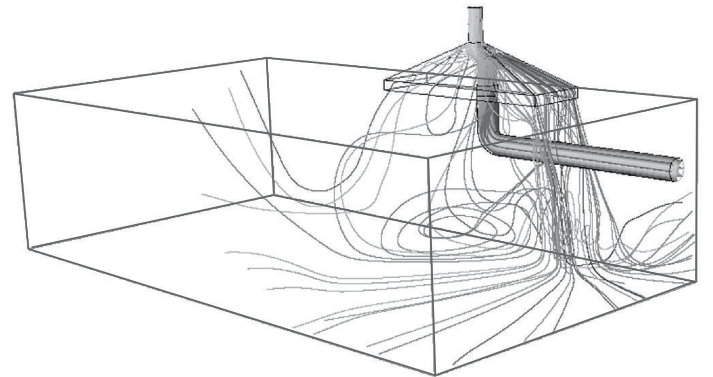

FIGURE 8: Predicted trajectories of particles injected from the duct pipe inlet.

particles injected from the duct pipe inlet were estimated to be deposited on the inner wall of the duct pipe and the surface of the canopy hood. Particles could be lost in a duct pipe, due to turbulent deposition, sedimentation, inertial deposition, 

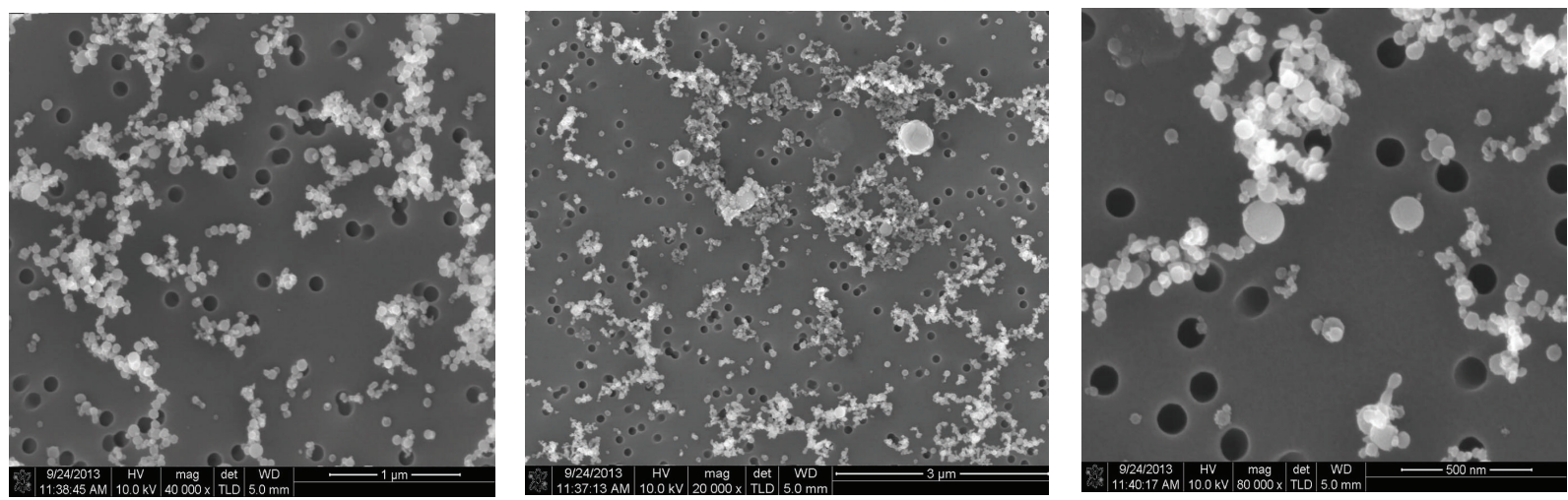

FIGURE 9: SEM images of powders sampled in the $\mathrm{TiO}_{2}$ manufacturing laboratory.

diffusion, and so forth. In addition, particle loss could be exacerbated in an elbow junction, due to the development of the secondary flow. Additionally, some of the particles exiting the outlet of the duct pipe were estimated to be deposited on the canopy hood. Because piling of particles on a surface in high airflow may result in the problem of particle reentrainment, the duct pipe and canopy hood need to be cleaned or replaced periodically.

3.5. Source Analysis from SEM Images. Figure 9 shows SEM images of nanopowders sampled from laboratory air via the Isopore filters (pore size $100 \mathrm{~nm}$ ). Most particles were spherical $\mathrm{TiO}_{2}$ [13]. The diameters of the primary particles ranged from 20 to $150 \mathrm{~nm}$. From Figure 4(a), the geometric mean diameter in the laboratory was approximately $40 \mathrm{~nm}$ with polydisperse size distribution. From the SEM image, it was also possible to estimate that many particles were suspended in the air as a form of aggregate, partially by coagulation in the flame zone during the synthesis process and also by reentrainment of aggregate dusts detached from the outlet of the flexible wall-duct.

\section{Conclusions}

In this study, we investigated nanopowder exposure in a laboratory that uses flame synthesis to manufacture $\mathrm{TiO}_{2}$. The $\mathrm{TiO}_{2}$ nanopowders were collected by a bag filter system for subsequent harvesting. During the manufacturing process, we found high concentrations of nanopowders within the laboratory as a result of low collection efficiency of the bag filter, exacerbated by the lower flow rate of the receiving extraction hood. This was confirmed by CFD simulation, which predicted that large amounts of nanopowders would be released from the bag filter system and be recirculated within the laboratory.

It is noted that the type of equipment used for harvesting nanomaterials is very important in avoiding nanomaterial exposure in manufacturing facilities or workplaces. The performance of harvesting equipment should exceed HEPA grade. In addition, the local hood system should be of appropriate specification and sufficient capacity to fully exhaust the air flow discharged from the harvesting equipment.

\section{Conflict of Interests}

The authors declare that there is no conflict of interests regarding the publication of this paper.

\section{Acknowledgments}

The authors acknowledge the financial support of the Ministry of Trade, Industry and Energy (MOTIE), Republic of Korea, for the National Platform Technology Project (10034758), and that of the Korea Institute of Science and Technology (KIST) for the Institutional Program (2E25290).

\section{References}

[1] G. Ramachandran, M. Ostraat, D. E. Evans et al., "A strategy for assessing workplace exposures to nanomaterials," Journal of Occupational and Environmental Hygiene, vol. 8, no. 11, pp. 673685, 2011.

[2] T. M. Peters, S. Elzey, R. Johnson et al., "Airborne monitoring to distinguish engineered nanomaterials from incidental particles for environmental health and safety," Journal of Occupational and Environmental Hygiene, vol. 6, no. 2, pp. 73-81, 2008.

[3] J. H. Han, E. J. Lee, J. H. Lee et al., "Monitoring multiwalled carbon nanotube exposure in carbon nanotube research facility," Inhalation Toxicology, vol. 20, no. 8, pp. 741-749, 2008.

[4] J. H. Lee, S.-B. Lee, G. N. Bae et al., "Exposure assessment of carbon nanotube manufacturing workplaces," Inhalation Toxicology, vol. 22, no. 5, pp. 369-381, 2010.

[5] M. M. Dahm, D. E. Evans, M. K. Schubauer-Berigan, M. E. Birch, and J. A. Deddens, "Occupational exposure assessment in carbon nanotube and nanofiber primary and secondary manufacturers: mobile direct-reading sampling," Annals of Occupational Hygiene, vol. 57, no. 3, pp. 328-344, 2013.

[6] D. E. Evans, B. K. Ku, M. E. Birch, and K. H. Dunn, "Aerosol monitoring during carbon nanofiber production: mobile directreading sampling," Annals of Occupational Hygiene, vol. 54, no. 5, pp. 514-531, 2010.

[7] A. D. Maynard, P. A. Baron, M. Foley, A. A. Shvedova, E. R. Kisin, and V. Castranova, "Exposure to carbon nanotube material: aerosol release during the handling of unrefined single-walled carbon nanotube material," Journal of Toxicology and Environmental Health Part A, vol. 67, no. 1, pp. 87-107, 2004. 
[8] J. H. Lee, M. Kwon, J. H. Ji et al., "Exposure assessment of workplaces manufacturing nano-sized $\mathrm{TiO}_{2}$ and silver," Inhalation Toxicology, vol. 23, no. 4, pp. 226-236, 2011.

[9] J. Dasch, J. D’Arcy, A. Gundrum, J. Sutherland, J. Johnson, and D. Carlson, "Characterization of fine particles from machining in automotive plants," Journal of Occupational and Environmental Hygiene, vol. 2, no. 12, pp. 609-625, 2005.

[10] T. M. Peters, W. A. Heitbrink, D. E. Evans, T. J. Slavin, and A. D. Maynard, "The mapping of fine and ultrafine particle concentrations in an engine machining and assembly facility," Annals of Occupational Hygiene, vol. 50, no. 3, pp. 249-257, 2006.

[11] J. H. Ji, D. Woo, S.-B. Lee et al., "Detection and characterization of nanomaterials released in low concentrations during multiwalled carbon nanotube spraying process in a cleanroom," Inhalation Toxicology, vol. 25, no. 14, pp. 759-765, 2013.

[12] J. H. Ji, J. B. Kim, G. Lee, and G. N. Bae, "Nanomaterial release characteristics in a single-walled carbon nanotube manufacturing workplace," Journal of Nanoparticle Research, vol. 17, no. 2, article 77, 2015.

[13] H. Park, H. S. Jie, B. Neppolian et al., "Preparation of highly active $\mathrm{TiO}_{2}$ nano-particle photocatalysts by a flame aerosol method for the complete oxidation of 2-propanol," Topics in Catalysis, vol. 47, no. 3-4, pp. 166-174, 2008. 

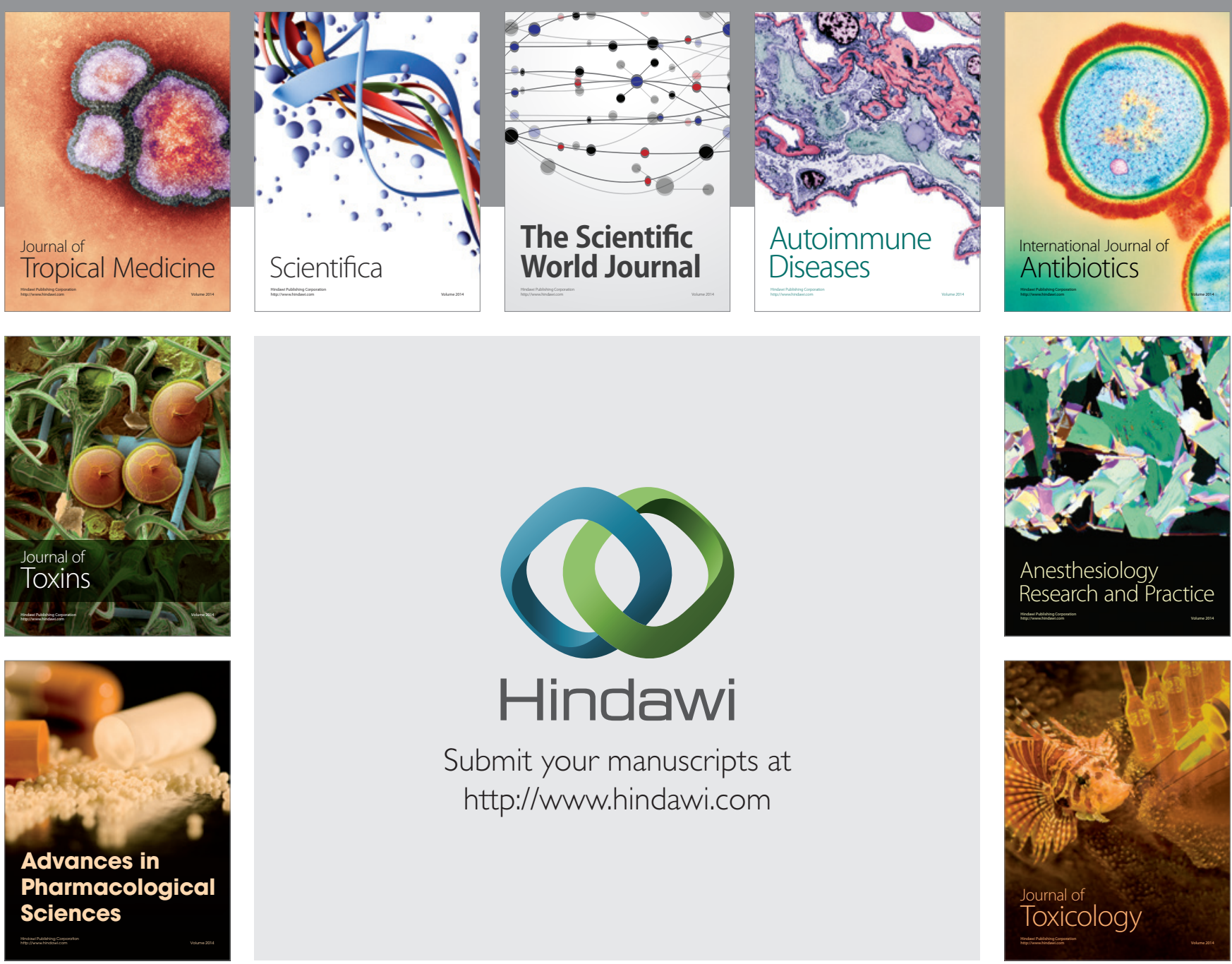

\section{Hindawi}

Submit your manuscripts at

http://www.hindawi.com
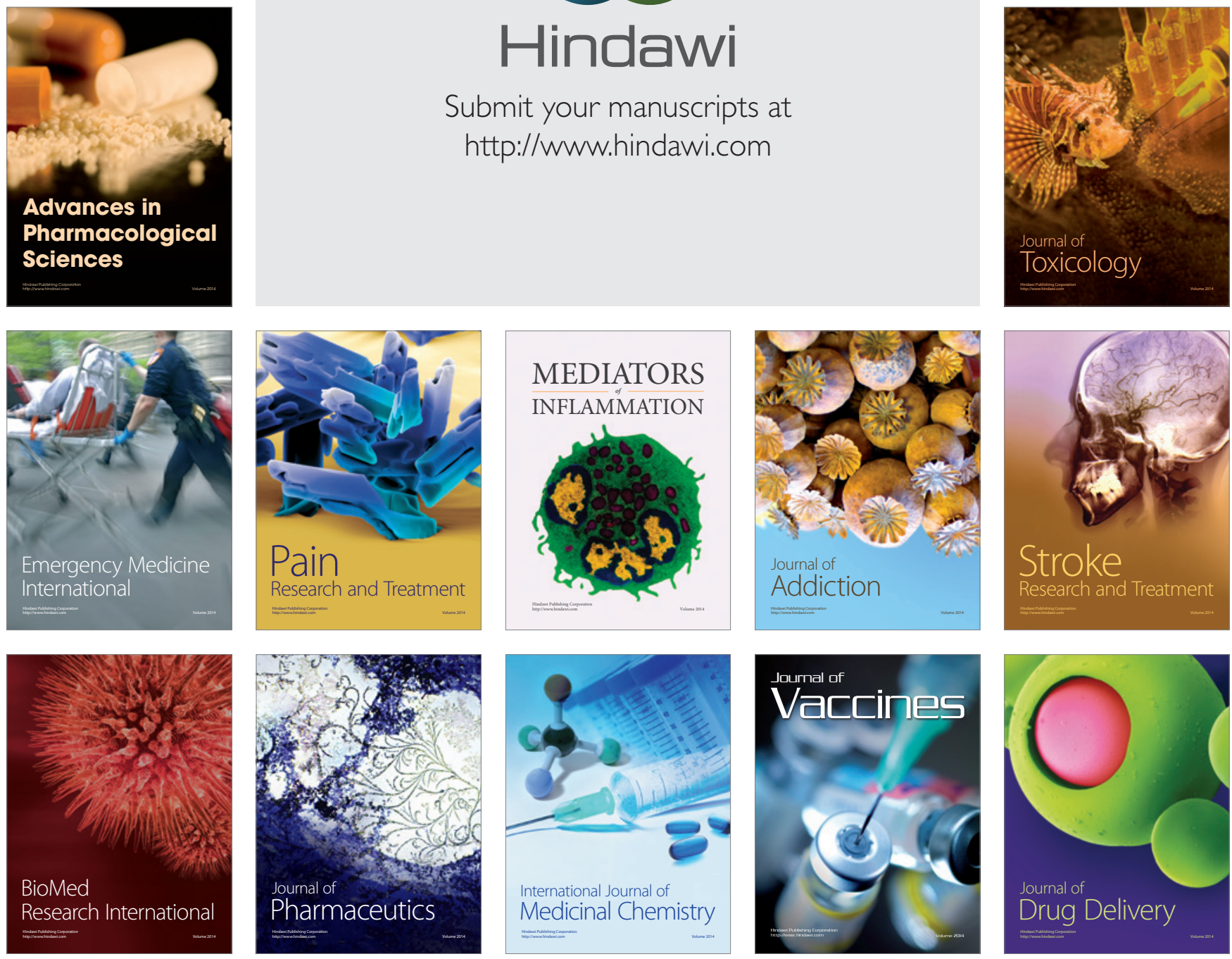